\title{
O método direto para o ensino de inglês no Brasil: instituição e recepção
}

\author{
Rodrigo Belfort Gomes ${ }^{I}$
}

Resumo: O método direto para o ensino de inglês foi criado no final do século XIX, com base nos estudos da nova ciência, a fonética. Com foco no desenvolvimento das habilidades orais, audição e fala, o método era completamente antagônico ao anterior e proibia o ensino dedutivo da gramática, tradução e uso da língua materna. Instituído no Brasil no ano de 1931, pela Reforma Francisco Campos, foi o primeiro método a ser definido através da legislação no país. Revolucionário para a época, o método direto ganhou grandes defensores no Brasil. Assim, é objetivo desse artigo, analisar a lei que definiu o método direto como o de eleição para o ensino das línguas vivas no Brasil, além de perceber como se deu a sua recepção por educadores, que escreveram livros sobre esse tipo de ensino no país.

Palavras-chave: Método direto, ensino de inglês, Reforma Francisco Campos, recepção

\section{The direct method of English teaching in Brazil: institution and reception}

\begin{abstract}
The direct method of English teaching was established in the late nineteenth century, based on studies of the new science, phonetics. Focusing on the development of oral skills, listening and speaking, the method was completely antithetical to the previous and forbade deductive grammar teaching, translation and use of the mother tongue. It was established in Brazil in 1931, by the Francisco Campos Reform. It was the first method to be defined by law in the country. Revolutionary for the time, the direct method gained great defenders in Brazil. Thus, it is the purpose of this article, to examine the law that defined the direct method as the election to the teaching of modern languages in Brazil, and to analyze how its reception happened by educators who have written books about this kind of education in the country.
\end{abstract}

Keywords: direct method, English teaching, Francisco Campos Reform, reception

Artigo recebido em 25/03/2016 e aprovado em 05/04/2016. 


\section{O que é o método direto}

Dentro da história do ensino de inglês como língua estrangeira, diversos métodos e abordagens se destacaram até chegarmos na atual era do pós-método. Os métodos surgem, em sua maioria, como forma de suprimir as "falhas" do que estava em vigência, mediante demandas da sociedade em um contexto histórico-educacional específico. O método direto não foge à essa ideia, ao tentar inovar, trazendo a centralidade das suas práticas para o desenvolvimento da oralidade, no ápice do desenvolvimento da nova ciência, a fonética.

Anterior à criação do método direto, no final do século XIX, o método da gramática e tradução estava em voga. Este método, para Larsen-Freeman ${ }^{\text {II }}$, outrora denominado método clássico, por ter sido utilizado para o ensino de idiomas como o latim e o grego, era utilizado para possibilitar aos alunos a leitura e consequente tradução de textos da literatura clássica, uma vez que a linguagem literária era considerada mais importante do que a linguagem oral. De acordo com essa autora, acreditava-se que esse tipo de ensino era capaz de possibilitar o crescimento intelectual dos discentes e, para que esse objetivo fosse alcançado, os alunos precisariam aprender as regras gramaticais, de forma dedutiva, através da memorização e posterior aplicação de regras, bem como memorizar palavras relacionadas ao texto, juntamente com a sua tradução. As habilidades orais recebiam muito menos atenção por parte do professor, e a pronúncia, pouquíssima ou nenhuma.

Celce-Murcia ${ }^{\text {III }}$ listou, em sua obra, alguns conceitos acerca do método da gramática e tradução. Destes, destacam-se os seguintes: as instruções eram dadas na língua materna, havia pouco uso da língua estrangeira para a comunicação, o foco estava nos exercícios gramaticais e textos difíceis eram lidos desde o início.

Pode-se dizer, então, que o método da gramática e tradução, cujo nome é auto explanatório, estava baseado na memorização de regras e palavras descontextualizadas, visando a leitura. Saber inglês, nesse contexto, era saber ler em língua inglesa, bem como traduzir e conhecer as regras gramaticais. É interessante apontar que muitas das práticas desse método ainda são utilizadas em escolas regulares, em que o ensino tende a se basear no estudo das regras gramaticais pelas regras gramaticais, muitas vezes dissociadas do seu uso prático.

O desenvolvimento da fonética e os estudos dos sons da língua inglesa, a partir da segunda metade do século XIX, em meados da década de 1880, através dos trabalhos realizados pela Associação Fonética Internacional, e dos importantes panfletos publicados por teóricos como Wilhelm Viëtor, Paul Passy, Otto Jespersen e Henry Sweet, criou terreno fértil para um acontecimento único na história do ensino das línguas: o Movimento da Reforma. De acordo com Howatt e Widdowson ${ }^{\mathrm{IV}}$, com a duração de aproximadamente vinte anos, esse importante movimento aconteceu de forma interdisciplinar, em um momento em que o interesse dos estudiosos da fonética tornou-se igual ao interesse dos professores por essa nova ciência que estava avançando rapidamente. A base da Reforma era formada por uma tríade, a saber, a primazia da fala, a centralização dos textos conectados, em detrimento do uso de frases isoladas, e a prioridade máxima dada às habilidades orais em sala de aula. Esses elementos são diretamente contrários ao método em voga na época, o da gramática e tradução.

De acordo com Celce-Murcia ${ }^{\mathrm{V}}$, o método direto foi uma reação ao método da gramática e tradução, que se mostrou ineficaz em formar aprendizes capazes de se comunicar na língua estrangeira. Como a tradução não era permitida na sala de aula, o professor, em geral nativo do idioma em questão, não precisava saber a língua mãe dos alunos, o que possibilitava turmas com discentes de diversas nacionalidades. Não somente a gramática era trabalhada de forma indutiva, como também as questões culturais envolvidas no idioma eram abordadas. Para os defensores do método direto, os textos literários são objetos de leitura por 
prazer, não fonte de exemplos para regras gramaticais exaustivamente trabalhadas no método predecessor.

O método direto surgiu, então, de maneira completamente antagônica ao da gramática e tradução, apoiado nos estudos fonéticos, que ocasionaram a criação do IPA (International Phonetic Alphabet) - Alfabeto Fonético Internacional, conjuntos de símbolos que representam os sons do inglês, que serviram de base para os professores que desejavam um método que possibilitasse o desenvolvimento das habilidades orais (audição e fala). O método que parecia revolucionário, exigiria muito mais dos professores, que agora teriam que falar a língua fluentemente, ministrar as aulas totalmente em inglês, bem como ter uma pronúncia perfeita e conhecer os símbolos fonéticos.

Embora tenha sido criado no final do século XIX, o método direto chegou oficialmente no Brasil em 1931, como parte das reformas educacionais propostas no ministro da educação e saúde pública, Francisco Campos, no governo provisório de Getúlio Vargas, à frente dos Estados Unidos do Brasil. É interessante apontar que esse foi um importante marco para o ensino das línguas vivas no país, uma vez que foi a primeira vez em que um método de ensino foi definido e detalhado através da legislação.

Assim, é objetivo desse artigo, analisar a legislação que instituiu o método direto como de eleição para o ensino das línguas vivas no Brasil, contrastando-a com a recepção deste método entre alguns professores, que também foram importantes autores de livros sobre o ensino das línguas vivas no país.

\section{$O$ contexto da reforma de 1931}

O ano de 1931 é, sem dúvidas, um ano de definições muito importantes para a educação brasileira, dentro do governo provisório de Getúlio Vargas, que havia chegado ao poder através da Revolução de 30, marcando, assim, o final da primeira república e iniciando a nova $^{\mathrm{VI}}$. Foi em 31 que o ministro do recém-criado Ministério dos Negócios da Educação e Saúde Pública, Francisco Campos, propôs a Reforma Francisco Campos que, entre outras coisas, redefiniu o ensino secundário no Brasil, além de instituir o método direto como método oficial para o ensino das línguas vivas. A questão educacional esteve na pauta do governo de Vargas desde o início, e sua maior intenção era a de criar "uma elite mais ampla, intelectualmente mais preparada"VII.

Através do Decreto n. 19.890, de 18 de abril de 1931, Francisco Luís da Silva Campos reestruturou todo o ensino secundário no Brasil, reconhecendo o Colégio Pedro II como instituição oficial do ensino secundário. Pela referida lei, o curso secundário foi dividido em dois cursos seriados, sendo eles o fundamental e o complementar. $\mathrm{O}$ curso fundamental foi distribuído em cinco anos, tendo o ensino de inglês ficado restrito a segunda, terceira e quarta séries, enquanto o francês estava presente nas quatro primeiras, a única disciplina de língua estrangeira ensinada na primeira série ${ }^{\mathrm{VIII}}$.

Contemporaneamente à Reforma Francisco Campos e com grande importância para a educação brasileira, tem-se o movimento da Escola Nova, que pode ser entendido como o conjunto de ações e textos divulgados por um grupo de intelectuais conhecidos como Pioneiros da Educação, preocupados com o desenvolvimento educacional do Brasil, e que, motivados pelas produções feitas, impulsionaram uma série de medidas, principalmente em decorrência da ocupação de cargos de ministério, com a consolidação de algumas ideias como educação para todos, ensino técnico, educação moral e cívica e Escola Normal. A partir de 1937, segundo Horta ${ }^{\mathrm{IX}}$, as ações do Estado tiveram objetivos bem claros, a exemplo de 
"utilizar a educação como instrumento para inculcar na infância e na juventude os princípios do Estado Novo e como uma luta ideológica".

Entre os documentos publicados nesse período, destaca-se o "Manifesto dos Pioneiros da Educação Nova", redigido por um grupo de intelectuais, entre os quais Fernando de Azevedo, Anysio Teixeira, Cecília Meireles, Paschoal Lemme e Delgado de Carvalho. De acordo com o teor desse manifesto, a educação integral era direito de qualquer indivíduo, devendo o Estado perceber a educação nos seus mais variados graus e entendê-la como uma função social e pública. O Estado deveria, dessa forma, trabalhar em parceria com a família, na colaboração efetiva entre pais e escola. Diante desse direito, cabia ao Estado organizar uma escola acessível em todos os graus, aos que viviam em condições econômicas inferiores, chegando-se, assim, à ideia de escola comum ou única, que não permita apenas a entrada das minorias que possuem privilégios econômicos. A laicidade, gratuidade, obrigatoriedade e coeducação são qualidades de destaque nesse modelo educacional e deveriam estar presentes na escola única, ficando a escola secundária ainda destinada à formação da elite.

A movimento da Escola Nova aconteceu de forma concomitante com a instauração do método direto como oficial para o ensino das línguas estrangeiras e estava em total consonância com a fase desenvolvimentista que o país vivia, sendo o seu entendimento importante para a percepção das mudanças educacionais como um todo, envolto em um grande contexto sociocultural. Da mesma forma que os pioneiros da educação acreditavam ser capazes de promover uma mudança estrutural no ensino, os defensores do método direto lançaram as bases para uma nova metodologia do ensino de línguas, que, se efetivada, provocaria uma mudança e uma ruptura nas práticas desenvolvidas até então.

\section{A Primeira menção ao método direto na legislação brasileira}

A primeira menção ao método direto pode ser encontrada no Decreto n. 20.158, de 30 de junho de 1931. Tal documento versa sobre a organização do ensino comercial, regulamenta a profissão de contador e dá outras providências. Essa peça legislativa é destinada aos estabelecimentos de ensino técnico comercial e define, entre outras coisas, que "o ensino comercial constará de um curso propedêutico, dos cursos técnicos de secretário, guarda-livros, administrador-vendedor, atuário e de perito contador, além de um curso superior de administração e finanças e de um curso elementar de auxiliar de comércio"X . A disciplina de inglês fazia parte das disciplinas do curso propedêutico, dos cursos técnicos (inglês comercial) e do curso de auxiliar de comércio. $O$ inglês não estava presente apenas no curso superior de administração e finanças.

A regulamentação para o uso do método direto pode ser encontrada na orientação do curso propedêutico. A instrução para o primeiro ano era que o inglês deveria ser trabalhado através do "método direto, conduzindo o aluno a pensar no próprio idioma estudado. Exercícios elementares de conversação e redação. Gramática aplicada aos casos ocorrentes"XI. Para o segundo ano, "Continuação do programa anterior, intensificando-se os exercícios de composição oral e escrita, destinados à aquisição do vocabulário e à correção da pronúncia" ${ }^{\text {XII }}$. O ensino de inglês no terceiro ano, era reservado à

\footnotetext{
“intensificação do programa anterior, com frequentes exercícios de conversação, para que o aluno possa utilizar fluentemente o idioma. Exercício de tradução e versão. O ensino visará a linguagem corrente, afim de que à compreensão dos alunos se tornem facilmente acessíveis as publicações em língua estrangeira, que interessem ao comércio"XIII.
} 
O curso de auxiliar de comércio previa o ensino de inglês nos 2 anos, no primeiro a orientação era "Método direto, com exercícios de redação e de conversação"XIV e no segundo "Método direto, com exercícios de redação comercial e conversação"XV.

O documento tratava ainda de vários elementos importantes para a regulamentação dos cursos comerciais, como calendário letivo, a quantidade de aulas por semana, frequência, médias, documentação exigida para a realização da matrícula, além do perfil que era exigido para ingresso nas instituições de ensino, como atestados de sanidade e idoneidade moral.

É interessante perceber nesse decreto, o primeiro em que o método direto é mencionado, que há uma tentativa de estabelecer preceitos desse método, tais como o ensino indutivo, exercícios de conversação, pronúncia correta, mas o elemento exercício de tradução e versão, encontrado no plano do terceiro ano do curso propedêutico, demonstra que nem todas as práticas do método anterior deveriam ser abolidas, já que o método direto não permitia que o aluno utilizasse sua língua materna. Traduzir foi por muito tempo sinônimo de saber uma língua, tanto é que o método clássico visava possibilitar os homens a leitura dos clássicos literários. A tradução permaneceu proibida por muitos anos, pelo menos pelos teóricos do ensino de línguas estrangeiras, até que se tornou uma ferramenta à disposição do professor, a depender de seus objetivos, no final do século XX, com a abordagem comunicativa revisitada, continuando assim até os dias de hoje. Os cursos comerciais visavam formar mão de obra técnica para o desenvolvimento do país e para a escrita e compreensão de cartas comerciais, por exemplo, o que fez com que a tradução se tornasse importante. O contexto em que esse ensino está inserido nos leva a compreender o uso da tradução. Entretanto, é importante ressaltar que o ensino através do método direto e as práticas de tradução não são compatíveis.

\section{O Decreto n. 20.833 e a recepção do método direto por Chagas, Leão e Schmidt}

O método direto foi oficialmente instituído no Brasil através do Decreto n. 20.833, de 21 de dezembro de 1931, pelo ministro da educação e saúde pública, Francisco Luís da Silva Campos, como parte da reforma educacional assinada por ele que, dentre outras coisas, regulamentou o ensino secundário no Brasil. No programa ora apresentado, Campos ressaltou que, durante o ensino de uma língua estrangeira, "os factos mais notaveis da civilização de outros povos" ${ }^{\mathrm{XVI}}$ precisam ser destacados, pois não basta apenas o aluno ser capaz de ler textos e traduzir adequadamente os vocábulos, sendo crucial que o pensamento seja manifestado diretamente na língua estrangeira, sem que se recorra ao português. Para tanto, "é mister applicar-se o methodo directo intuitivo, isto é, ensinar a lingua estrangeira na propria lingua estrangeira"

Apesar de propor o ensino intuitivo, diferentemente do que se empregava até então, algumas práticas difundidas no método da gramática e tradução foram também destacadas, como, por exemplo, o incentivo para que os primeiros exercícios dos alunos fossem através do ditado, com subsequente correção da pronúncia. Merece também destaque a recomendação de que os textos em língua estrangeira fossem decorados, devendo o aluno, no entanto, ser incentivado a fazer pequenas alterações, como mudança de pronomes e flexão de verbos, sendo também interessante que alguns poemas pudessem ser recitados de cor ${ }^{\mathrm{XVIIII}}$. A decoreba foi um elemento muito forte do método anterior, em que se esperava que os alunos memorizassem não só as palavras, como também sua tradução e as regras gramaticais. Para os teóricos do método direto, os textos literários deveriam ser objeto de leitura por prazer e não por obrigação. Desta forma, tal prática de recitar de cor não se coaduna com os preceitos do método recém-estabelecido e mostra a força que o método anterior ainda possuía. De fato, o ensino intuitivo leva mais tempo para trazer resultados, uma vez que o aluno deve ser levado a 
perceber o uso de determinada estrutura, ao passo que o aluno que decora e repete o que memorizou, aparenta ter obtido sucesso mais rapidamente, mas não passa de um repetidor que muitas vezes não compreende o que está falando ou é incapaz de realizar uma simples flexão de tempo verbal na frase. Algo que até Rousseau, em pleno século XVIII, já criticava, "Coisas! Coisas! Eu nunca me canso de repetir que nós atribuímos poder demais às palavras. Com nossa educação de balbucio, produzimos apenas balbuciadores"XIX

A utilização da gramática, bem como da tradução, ferramentas muito comuns no método utilizado até então, estavam presentes nas recomendações de Campos, tendo sido colocadas, no entanto, como acessórias para o desenvolvimento dos alunos, ou seja, a importância da gramática foi mantida, necessitando situá-la no processo de ensino de uma língua estrangeira.

Para que não se mantenham distantes dos factos lingüisticos, as regras de grammatica só se aprenderão inductivamente, sem formalismo e após o conhecimento pratico, rigoroso e seguro dos factos. Acompanhando o desenvolvimento da faculdade de elocução, tornar-se-á naturalmente cada vez mais sensivel a necessidades das regras gramaticais, será o conhecimento desta tanto mais reclamado quanto mais numerosas forem as palavras aprendidas.

Só depois de alcançado na lingua estrangeira conhecimento bastante desenvolvido, convirá introduzir-se o estudo comparativo das duas línguas, usando-se, para isto, algumas traducções e, depois, em menor numero do que estas, versões. ${ }^{\mathrm{XX}}$

O ensino de línguas vivas foi mais detalhado através das instruções publicadas para o exercício desse Decreto, o n. 20.833, e nas quais o método direto foi explicado. Já no artigo $1^{\circ}$, ficou determinado que o ensino de língua estrangeira deveria se dar na própria língua que se deseja ensinar, desde o primeiro dia de aula, havendo a indicação dos escritores contemporâneos mais recomendáveis, e que, dessa forma, deveriam ser lidos. A língua portuguesa só poderia ser utilizada excepcionalmente, quando houvesse a necessidade de uma explicação indispensável na língua materna. Dois cargos de professores foram criados, o de auxiliar, responsável pelo acompanhamento individualizado dos alunos, e o de professor dirigente, responsável pela manutenção da uniformidade no ensino, conduzido pelos auxiliares. XXI

As turmas eram originariamente compostas por uma média de 45 a 50 alunos e, sabendo-se que o trabalho com o método direto era árduo, uma divisão em grupos menores, com até 15 alunos, fazia-se necessária. Essas turmas, invariavelmente, apresentavam alunos com níveis diferentes de proficiência, fato este que se tentou resolver através de testes de inteligência e de aproveitamento, como forma de se obter uma homogeneização das classes. A divisão das classes em turmas de no máximo 15 alunos era imprescindível para assegurar o aprendizado, uma vez que os discentes precisariam de mais tempo e maior acompanhamento para que a oralidade pudesse ser trabalhada, respeitando-se o nível dos alunos, uma vez que a homogeneidade das classes, no que se refere à fluência observada, não era verificada. "Haveria classes mais fortes e classes mais fracas, nas quais, o esforço do mestre se estenderia mais ou menos igualmente por todos. Umas classes caminhariam mais depressa e outras mais devagar, todas, com segurança e êxito"XXII

A defesa das práticas orais nessa época é justificada pelas teorizações feitas na segunda metade do século XIX, através da Reforma ${ }^{\text {XXIII }}$, sobre a fonética, o estudo dos fonemas e o ensino do idioma estrangeiro pelo próprio idioma. $\mathrm{O}$ valor dado à pronúncia, nesse novo método, era enorme, tanto que Leão ${ }^{\text {XIV }}$ acreditava que a preocupação com a pronúncia perfeita, aquela que deveria se assemelhar o máximo possível a de um falante nativo, 
precisava ser buscada. Para o autor, o professor deveria impor sua voz, de modo que a classe inteira pudesse ouvir claramente todas as sílabas pronunciadas por ele e desenvolvesse, assim, a educação dos ouvidos e o exercício das cordas vocais (vozeamento/desvozeamento), por conseguinte. Os docentes deveriam sempre ler as novas palavras e fazer com que os alunos repetissem antes da prática da escrita, o que faria com que a habilidade de repetição dos discentes fosse utilizada ao máximo. A importância atrelada à fonética deve estar associada à busca pela pronúncia ideal, que deve ser considerada como um grande progresso alcançado pela pedagogia moderna.

Antônio Carneiro Leão (1887-1966) foi um educador nascido em Recife, que acumulou em seu currículo a função de professor universitário, diretor geral de Instrução Pública, professor dirigente do ensino de francês no Colégio Pedro II e ocupante da cadeira 14 da Academia Brasileira de Letras. Além disso, Carneiro Leão foi autor de uma reforma educacional no estado de Pernambuco que levou o seu nome. Tal reforma visava definir um novo modelo de ensino, que contribuísse para civilizar e modernizar a sociedade e cujo cerne estava na qualificação profissional ${ }^{\mathrm{XXV}}$. Leão foi um dos mais árduos defensores do método direto. Para ele, "não é apenas, porém, no ponto de vista cultural, social e internacional que o método direto domina. Êle contribue tambem para a educação estetica. Influe, pela sonoridade da lingua falada, pela musicalidade da expressão oral, no proprio senso do ritmo"XXVI . Leão ${ }^{X V I I}$ considerava que o método direto tinha o intuito, desde o primeiro dia de aula, de ensinar a língua correta e pura, e que a busca pela pronúncia igual a de um nativo era o objetivo dos professores do método direto XXVIII.

Segundo o site dedicado à História do Ensino das Línguas no Brasil, do programa de pós-graduação da UnB, Raimundo Valnir Cavalcante Chagas (1921-2006), que trabalhou no Conselho Nacional, desempenhando importante papel na idealização da LDB de 1971, além de ter sido um dos fundadores da Universidade de Brasília, também realçou a importância da valorização dos estudos fonéticos, em sua obra Didática Especial de Línguas Modernas, que data do ano de 1957. Chagas destacou ter sido esta a primeira tentativa de trazer a fonética para a sala de aula, considerada a grande inovação nos estudos de ensino de línguas, bem como a sistematização do ensino da língua estrangeira na própria língua. Nos primeiros anos, o ensino deveria focar no processo de familiarização dos alunos com o sistema fonético e fonológico da língua estudada, além da aquisição de vocabulário através de situações corriqueiras e do seu próprio ambiente. Em seguida, o ensino tinha como objetivo a leitura e interpretação de obras dos séculos XVIII, XIX e XX, com alguns exercícios de versão e tradução, com uso moderado de dicionários. A gramática só deveria ser trabalhada de forma indutiva e após o conhecimento prático.

Chagas ${ }^{\mathrm{XIX}}$ creditou tanto valor à reforma Francisco Campos, no tocante ao ensino das línguas, que afirmou que esse ensino precisaria ser analisado utilizando o ano de 1931 como marco histórico e que era preciso perceber a fase antes e depois de 31. Para esse autor, a Reforma Francisco Campos foi a primeira tentativa de modernizar o estudo das línguas modernas, muito embora a carga horária insuficiente, bem como "a carência absoluta de professôres cuja formação lingüística e pedagógica ensejasse o cumprimento de programa tão 'avançado' foram circunstâncias que transformaram as Instruções de 1931 em autêntica letra morta "XXX . Os problemas relatados por Chagas em 1957, como carga horária muito reduzida e falta de professores capazes de ministrar aulas no formato do método direto já havia sido apontados por Leão, em 1935. Embora descrente da efetivação do método direto no Brasil, Chagas ${ }^{X X X}$ apontou para o fato de que novas ideias haviam entrado no país, em que ainda se estudavam as línguas vivas como as mortas. Diferente de Leão, fervoroso defensor do método, que chegou a escrever $\mathrm{O}$ ensino das línguas vivas ainda no furor do momento, em 1935, Chagas XXXII, refletiu sobre a implementação do método 25 anos depois e, embora Cadernos do Tempo Presente, n.23, mar./abr. 2016, p. 113-125| http://www.seer.ufs.br/index.php/tempo 
aponte falhas, como a falta de estrutura das salas de aula de línguas, compreende a euforia de Leão, frente ao que vinha sendo feito com as línguas e o que havia sido proposto pela legislação educacional, ao creditar que, para a época que foi adotado, o método "encerrava quase todos os progressos até então registrados pela didática das línguas".

Maria Junqueira Schmidt foi professora, historiadora e escritora, escreveu desde biografias de importantes personagens femininas da nobreza brasileira, como livros sobre educação, ensino de línguas e literatura. Ela é autora de $\mathrm{O}$ ensino científico das línguas modernas, de 1935, mesmo ano de publicação da obra de Leão. Segundo Schmidt XXXIII, deveria ser cobrado, o conhecimento e a distinção das classes gramaticais das palavras, bem como dos tempos verbais, da interpretação dos textos e das técnicas de pontuação e capitalização, para que pudesse auxiliar na aquisição de técnicas de leitura em língua estrangeira. Era necessário que o professor testasse seus alunos no começo do curso e, caso alguma deficiência fosse detectada, pedisse ajuda ao professor de português, para que tais deficiências fossem sanadas. Tratava-se, dessa forma, de uma comprovação da importância que a gramática deveria desempenhar para o ensino, sendo fundamental o conhecimento da gramática na língua materna. Com o conhecimento esperado que o aluno deveria apresentar ao final dos estudos, pode-se inferir que a mudança da metodologia de ensino não estava sendo acompanhada de um apagamento do ensino sistemático da gramática. Para ela

o método direto veiu repôr as coisas no seu lugar. Declarou imprescindível o estudo da gramática num curso integral de línguas, isto é, naquêle em que figura o quadruplo objetivo - ler, escrever, falar e entender, - e demonstrou a utilidade do mesmo, quando visa dar o conhecimento ativo e funcional das leis gramaticais ${ }^{\text {XXIV }}$.

A autora se mostrou favorável à revisão sistemática da gramática em estágios iniciais e à tradução literária nos estágios avançados, acreditando no poder de tais práticas para que o domínio da língua estrangeira fosse assegurado. Da mesma forma que Leão ${ }^{X X V}$, ela buscava a valorização das práticas voltadas para a oralidade, mas não propôs uma ruptura total da gramática, conforme defendido pelos preceitos do método, já que, segundo LarsenFreeman $^{\text {XXXVI }}$, Brown ${ }^{\text {XXXVII }}$ e Howatt e Widdowson ${ }^{\text {XXXVIII }}$, a gramática não poderia ser ensinada no método direto, apenas assimilada pela observação e por formas totalmente intuitivas, sem que nenhuma explicação se fizesse necessária.

Schmidt ${ }^{\mathrm{XXXX}}$ defendeu práticas totalmente intuitivas para o ensino da gramática, explicando que o método dedutivo só deveria ser empregado muito raramente e quando houvesse uma razão especial para o uso. Ao descrever como o ensino indutivo deve ser guiado, no entanto, percebe-se uma contradição. A autora declara que a explicação de regras é necessária para que o aprendizado seja assegurado, devendo-se ter o cuidado em não expor o aluno muito cedo a regras e memorizações. "O ensino da gramática só deve começar, aliás, depois que o aluno esteja familiarizado com a leitura pelo menos silenciosa do idioma estrangeiro, o que raramente se verifica antes do fim do primeiro trimestre de aula"XL.

Quatro são as formas defendidas pela autora para o ensino da gramática de forma eficaz: inicialmente, as formas gramaticais devem ser reconhecidas, sendo conveniente o seu uso no primeiro ano, sem a preocupação com o reconhecimento das regras; em um segundo estágio, tem-se o ensino incidental dos fenômenos gramaticais, através do qual as explicações são dadas na medida em que vão aparecendo na leitura, composição ou conversação, o que, segundo Schmidt ${ }^{\mathrm{XLI}}$, geraria certa insegurança no aluno, em decorrência da diversidade de casos sem seguimento. Em um terceiro momento, o ensino da gramática é conduzido de forma sistemática, já que, controversamente ao que havia sido defendida anteriormente, a 
gramática ensinada incidentalmente não bastava, pois o aluno precisaria ter noções claras e precisas da língua.

Chagas ${ }^{\mathrm{XLII}}$ sinalizava um fato que os mais entusiastas do método direto teimavam em não aceitar. Não bastava a mudança da metodologia a ser empregada nas salas de aula, sem que uma estruturação que envolvesse outras questões fosse também realizada, como, por exemplo, a divisão dos tempos das aulas de forma mais coerente com as necessidades do ensino de um idioma na própria língua estrangeira, já que, sem o acréscimo de uma carga horária necessária, a mudança da prática se tornava irreal, e a tendência em se perpetuar o ensino da gramática de forma puramente dedutiva e a tradução tendiam a continuar.

\section{Algumas considerações}

O método direto trouxe para o ensino das línguas vivas uma proposta mais intuitiva de ensino, que deveria acontecer de uma forma mais natural, através de práticas contextualizadas e que trouxessem situações comunicativas e que a gramática fosse trabalhada sempre de maneira indutiva e nos casos ocorrentes. O método veio embasado pelas descobertas dos estudos científicos da fonética e possibilitou um cruzamento entre o anseio dos professores por um método mais natural e que privilegiasse a oralidade e o desejo de desenvolvimento da nova ciência pelos teóricos. A tradução, que por muito tempo esteve presente nas salas de aula das línguas vivas, deveria ser abolida e o ensino de vocabulário não deveria mais ser feito através de criação de listas de palavras retiradas de um texto, de maneira descontextualizada.

As ideias propagadas pela Europa com o movimento da Reforma, a demanda por uma educação mais intuitiva, desejada há muito tempo, por teóricos como Rousseau, Locke e Pestalozzi, e os ideias da Escola Nova, criaram um cenário propício para a institucionalização do método direto no Brasil. Enquanto alguns teóricos defendiam o método, como Leão e Schmidt, alguns anos mais tarde Chagas conseguiu perceber que a proposta de trazer um método tão distinto do que havia sendo utilizado era, no mínimo, ousada para as condições da época, tanto de infraestrutura das escolas, como de preparação e oferta de professores capacitados. A Reforma Francisco Campos mostrou-se em consonância com muitas das ideias da época, tanto educacionais, como políticas, mas práticas tão comuns e estabelecidas nas salas de aula seriam muito difíceis de serem retiradas, e, dentre elas, temos a tradução e o ensino dedutivo da gramática. Até porque a tradução e versão de textos estavam presentes nos próprios programas de ensino e o ensino dedutivo, disfarçado de indutivo, estava presente no discurso de professores como Maria Junqueira Schmidt. Assim, é difícil esperar que uma metodologia que tenta romper bruscamente com práticas seculares seja seguida em sua totalidade, principalmente quando ela é prescrita na própria legislação, utilizando elementos do método anterior. A leitura e tradução de clássicos literários continuava a ser recomendada, até porque Vargas destinava o ensino secundário para a formação das elites e a intitulada alta cultura dependia também da leitura dos cânones estrangeiros. Para o estudo comercial, o ensino deveria possibilitar o aluno traduzir e escrever textos de interesse do comércio. A prescrição do método direto com a inclusão de elementos estranhos a ele tinha, assim, objetivos claros.

É interessante ressaltar que as ideias presentes na reforma educacional de 31 , no que diz respeito ao ensino das línguas vivas, podem não ter sido aplicadas em sua totalidade, mas, 
pelo menos, o anseio por um ensino mais intuitivo tinha sido lançado de forma oficial no Brasil.

\section{NOTAS}

\footnotetext{
${ }^{\text {I }}$ Mestre em Letras pela Universidade Federal de Sergipe. Doutorando em Educação pelo Programa de Pósgraduação em Educação da UFS.
}

II LARSEN-FREEMAN, Diane. Techniques and principles in language teaching. Oxford: OUP, 2011.

III CELCE-MURCIA, Marianne (edt.). Teaching English as a second or foreign language. USA: Heinle \& Heinle, 2001.

${ }^{\mathrm{IV}}$ HOWATT, Anthony Philip Reid; WIDDOWSON, H. G. A history of English language teaching. $2^{\mathrm{a}}$ ed. Oxford: Oxford University Press, 2009.

v Idem a III

${ }^{V I}$ FAUSTO, Boris. História concisa do Brasil. São Paulo: Editora da Universidade de São Paulo, 2012.

VII Idem a VI. P. 188.

VIII BRASIL. Decreto n. 19.890, de 18 de abril de 1931. Diário Oficial da União, Brasília, DF, Seção 1, p. 20626, 1931.In: < http://www.planalto.gov.br/ccivil_03/decreto/1930-1949/D19890impressao.htm>

${ }^{\mathrm{Ix}}$ HORTA, José Silvério Baía. O hino, o sermão e a ordem do dia: regime autoritário e a educação no Brasil (1930-1945). Rio de Janeiro: Editora UFRJ, 1994. P. 293.

${ }^{\mathrm{x}}$ BRASIL. Decreto n. 20.158, de 30 de junho de 1931. In: Coleção das Leis de 1931 - volume II. Rio de Janeiro: Imprensa Nacional, 1942. P. 458-459.

${ }^{\mathrm{XI}}$ Idem a X. P. 460.

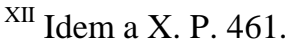

XIII Idem a X P. 461.

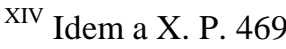

${ }^{\mathrm{xv}}$ Idem a X. P. 469

${ }^{\mathrm{XVI}}$ LEÃO. A. Carneiro. O ensino das línguas vivas: seu valor, sua orientação científica. São Paulo: Companhia Editora Nacional, 1935. P. 44.

XVII Idem a XVI. P. 45.

XVIII BRASIL. Ministério da Educação e Saúde Pública. Programas do ensino secundário baixados com a portaria de 30 de junho de 1931. Imprensa nacional, 1934.

xx Idem a XVI. P. 46.

ROUSSEAU, Jean-Jacques. Emile, or on education. London: Penguin, 1991.

XXI BRASIL. Decreto n. 20.833, de 21 de dezembro de 1931. Diário Oficial da União, Brasília, DF, Seção 1, p. 4, p. 4240-4241, 1931b. In: <http://www2.camara.leg.br/legin/fed/decret/1930-1939/decreto-20833-21dezembro-1931-508467-publicacaooriginal-1-pe.html>

XXII Idem a XVI. P. 280-281. 
XXIII Idem a IV.

${ }^{\text {XXIV }}$ Idem a XVI

XXV ARAÚJO, Cristina. “A Reforma Antônio Carneiro Leão no final dos anos de 1920”. Revista

Brasileira de História da Educação. v. 9. n. 1. p. 119-136. 2009.

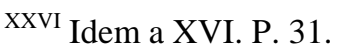

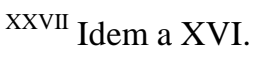

XxVIII As pesquisas da atualidade sobre o ensino de língua não abordam mais a questão do falante perfeito, uma vez que não há como se definir uma pronúncia perfeita no mundo globalizado com intensas trocas culturais, fala-se hoje em world English, não mais delimitando o inglês por países. Busca-se o desenvolvimento de competências, como o trabalho em prol de uma pronúncia que permita a comunicação entre os indivíduos. Já que, de acordo com Rajagopalan, a língua inglesa que circula no mundo, que serve de meio de comunicação entre os diferentes povos do mundo hoje, não pode ser confundida com a língua que se fala nos Estados Unidos, no Reino Unido, na Austrália ou onde quer que seja.

RAJAGOPALAN, Kanavillil. A geopolítica da língua inglesa e seus reflexos no Brasil. In: LACOSTE, Ives.; RAJAGOPALAN, Kanavillil. (Org.) A geopolítica do inglês. São Paulo: Parábola Editorial, 2005, pp. 135-159.

XxIx CHAGAS, R. Valnir C. Didática especial de línguas modernas. Companhia Editora Nacional: São Paulo, 1957.

${ }^{\text {XXX }}$ Idem a XXIX. P. 92.

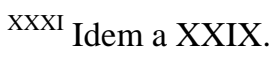

xxxII Idem a XXIX.

xxxIII SCHMIDT, Maria Junqueira. O Ensino Científico das Línguas Modernas. Briguiet \& Cia, 1935.

XXXIV Idem a XXXIII. P. 148.

${ }^{\text {xxxv }}$ Idem a XVI.

xxxvi Idem a II.

XxxVII BROWN, Douglas. Teaching by principles - an interactive approach to language pedagogy. $2^{\mathrm{a}}$ ed. New York: Pearson, 2001.

XxxVIII Idem a IV.

XXXIX Idem a XXXIII.

${ }^{\mathrm{XL}}$ Idem a XXXIII. P. 149.

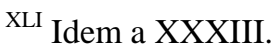

XLII Idem a XXIX.

\section{Referências}


ARAÚJO, Cristina. “A Reforma Antônio Carneiro Leão no final dos anos de 1920”.

Revista Brasileira de História da Educação. v. 9. n. 1. p. 119-136. 2009.

BRASIL. Decreto n. 19.890, de 18 de abril de 1931. Diário Oficial da União, Brasília, DF, Seção 1, p. 20626, 1931.In: < http://www.planalto.gov.br/ccivil_03/decreto/19301949/D19890impressao.htm>

BRASIL. Decreto n. 20.833, de 21 de dezembro de 1931. Diário Oficial da União, Brasília, DF, Seção 1, p. 4, p. 4240-4241, 1931. In: <http://www2.camara.leg.br/legin/fed/decret/19301939/decreto-20833-21-dezembro-1931-508467-publicacaooriginal-1-pe.html>.

BRASIL. Ministério da Educação e Saúde Pública. Programas do ensino secundário baixados com a portaria de 30 de junho de 1931. Imprensa nacional, 1934.

BRASIL. Decreto n. 20.158, de 30 de junho de 1931. In: Coleção das Leis de 1931 - volume II. Rio de Janeiro: Imprensa Nacional, 1942. P. 458-459.

BROWN, Douglas. Teaching by principles - an interactive approach to language pedagogy. $2^{\mathrm{a}}$ ed. New York: Pearson, 2001.

CELCE-MURCIA, Marianne (edt.). Teaching English as a second or foreign language. USA: Heinle \& Heinle, 2001.

CHAGAS, R. Valnir C. Didática especial de línguas modernas. Companhia Editora Nacional: São Paulo, 1957.

FAUSTO, Boris. História concisa do Brasil. São Paulo: Editora da Universidade de São Paulo, 2012.

HORTA, José Silvério Baía. O hino, o sermão e a ordem do dia: regime autoritário e a educação no Brasil (1930-1945). Rio de Janeiro: Editora UFRJ, 1994. P. 293.

HOWATT, Anthony Philip Reid; WIDDOWSON, H. G. A history of English language teaching. $2^{\mathrm{a}}$ ed. Oxford: Oxford University Press, 2009.

LARSEN-FREEMAN, Diane. Techniques and principles in language teaching. Oxford: OUP, 2011.

LEÃO. A. Carneiro. O ensino das línguas vivas: seu valor, sua orientação científica. São Paulo: Companhia Editora Nacional, 1935. P. 44.

RAJAGOPALAN, Kanavillil. A geopolítica da língua inglesa e seus reflexos no Brasil. In: LACOSTE, Ives.; RAJAGOPALAN, Kanavillil. (Org.) A geopolítica do inglês. São Paulo: Parábola Editorial, 2005, pp. 135-159.

ROUSSEAU, Jean-Jacques. Emile, or on education. London: Penguin, 1991.

SCHMIDT, Maria Junqueira. O Ensino Científico das Línguas Modernas. Briguiet

\& Cia, 1935.

\section{Sites consultados}

http://www.academia.org.br/academicos/antonio-carneiro-leao/biografia

http://www.helb.org.br/index.php?option=com_content\&view=article\&id=4:professor-valnirchagas \&catid=1065:1957\&Itemid=2

http://www.helb.org.br/index.php?option=com_content\&view=article\&id=207:mariajunqueira-schmidt\&catid=1113:1913\&Itemid=2 
O MÉTODO DIRETO PARA O ENSINO DE INGLÊS NO BRASIL: INSTITUIÇÃO E RECEPÇÃO

RODRIGO BELFORT GOMES 